\title{
KATA SERAPAN DAN ISTILAH ASING JOKO WIDODO DALAM DEBAT CALON PRESIDEN DAN WAKIL PRESIDEN 2019
}

\author{
Dwi Septiani \\ Prodi Sastra Indonesia \\ Universitas Pamulang \\ Jl. Surya Kencana No.1, Pamulang, Tangerang Selatan \\ surel: dosen01401@unpam.ac.id
}

\begin{abstract}
Abstrak
Penggunaan bahasa Indonesia tidak hanya wajib dikuasai oleh pengajar bahasa Indonesia, tetapi juga para pejabat negara, salah satunya adalah kepala negara. Sebagai suri teladan, alangkah eloknya menguasai bahasa asing seperti bahasa Inggris dan juga menguasai bahasa negara dan bahasa nasional, yakni bahasa Indonesia. Oleh sebab itu, sebagai kontrol untuk mengembangkan bahasa Indonesia, diperlukan banyak kajian bahasa yang berkaitan dengan variasi diksi dalam wacana lisan yang digunakan para elite politik dalam forum-forum resmi, misalnya dalam debat calon presiden dan wakil presiden. Penelitian ini bertujuan untuk mendeskripsikan variasi penggunaan kata serapan dan istilah asing yang diujarkan oleh Joko Widodo dalam debat calon presiden dan wakil presiden 2019 (debat ke-5). Jenis penelitian ini adalah deskriptif kualitatif. Data dalam penelitian ini berjumlah 107 data tuturan. Pada penelitian ini, ditemukan 35 data tuturan yang mengandung kata serapan (32, 7\%) dan 25 data tuturan yang mengandung istilah asing (23,4\%). Penggunaan kata serapan dan istilah asing yang dituturkan oleh Joko Widodo ketika debat calon presiden dan wakil presiden 2019 (debat ke-5) yang paling dominan adalah kosakata yang berasal dari bahasa Inggris.
\end{abstract}

Kata kunci: Kata serapan, istilah asing, Joko Widodo

\section{A. PENDAHULUAN}

Pada tahun 2019, masyarakat Indonesia telah menghadapi fenomena pesta demokrasi atau tahun politik, yakni diselenggarakannya pemilihan umum presiden dan wakil presiden serentak pada tanggal 17 April 2019 di masing-masing daerah. Dua pasangan calon presiden dan wakil presiden yang terpilih, yaitu pada nomor urut 01 ditempati oleh calon presiden Ir. H. Joko Widodo dengan wakilnya K.H. Ma'ruf Amin, dan calon presiden H. Prabowo dengan wakilnya Sandiaga Salahuddin Uno pada nomor urut 02.

Komisi Pemilihan Umum (KPU) bekerja sama dengan televisi pemerintah dan swasta untuk kelima kalinya menggelar forum debat calon presiden dan wakil presiden untuk ditayangkan secara langsung pada tanggal 13 April 2019 yang bertempat di Hotel Sultan, Jakarta. Pelaksanaan debat kelima ini menampilkan para peserta debat, yaitu kedua calon presiden dan wakil presiden 2019, dipandu oleh moderator Tomy Ristanto dan Balques Manisang, dihadiri oleh tokoh-tokoh agama dan tokoh-tokoh keilmuan, serta dihadiri para pendukung masing-masing calon peserta 
debat. Forum debat ini merupakan peristiwa nasional yang penting sebagai perwujudan dari demokrasi di Indonesia.

Momen pemilihan presiden and wakil presiden tahun 2019 cukup mendapat perhatian di kalangan masyarakat Indonesia dan juga internasional. Sebagai petahana, Joko Widodo memiliki gaya komunikasi yang khas. Oleh sebab itu, tidak perlu diragukan lagi bagaimana kekhususan bahasa lisan yang dimiliki Joko Widodo untuk mampu bersaing dalam debat. Bahasa dapat digunakan secara tulisan maupun lisan. Chaer (2012: 52) mengemukakan bahasa adalah satusatunya milik manusia yang tidak pernah lepas dari segala kegiatan dan gerak manusia sepanjang keberadaan manusia itu sebagai makhluk yang berbudaya dan bermasyarakat. Tidak ada kegiatan manusia yang tidak disertai oleh bahasa. Bahasa erat kaitannya dengan diksi dan gaya bahasa. Keraf (2006: 23) menyebutkan bahwa gaya bahasa yang dimiliki oleh seseorang merupakan bagian dari diksi bertalian erat dengan ungkapan-ungkapan yang individual atau karakteristik, atau memiliki nilai artistik tinggi. Namun, era globalisasi yang menjangkau Indonesia dalam proses masuknya lingkup dunia telah menuntut masyarakat untuk tidak terbatas dalam menggunakan bahasa (Septiani dan Manasikana, 2020)

Dengan demikian, gaya bahasa menjadi sebuah motif atau cara dalam mengungkapkan buah pikiran seseorang melalui bahasa secara khas yang dapat memperlihatkan jiwa dan kepribadisan pemakai bahasa (penulis bahasa), kemudian diwujudkan dengan cara pemilihan diksi secara tepat sehingga dapat membedakan individu satu dengan individu lainnya. Diksi sangat diutamakan dalam sebuah tulisan, di samping itu gaya bahasa juga mempunyai peranan penting. Keraf (2006:112) mengemukakan bahwa gaya bahasa adalah bagian dari diksi yang mempersoalkan cocok tidaknya pemakaian kata, frasa, atau klausa untuk menghadapi situasi tertentu. Oleh sebab itu, persoalan gaya bahasa meliputi semua hirarki kebahasaan. Keraf (2006:113) gaya bahasa merupakan cara mengungkapkan pikiran melalui bahasa secara khas yang memperlihatkan jiwa dan kepribadian penulis (pemakai bahasa).

Forum debat calon presiden dan wakil presiden dapat dikatakan sebuah wacana lisan, karena terdapat sebuah percakapan khusus yang formal dan suatu rangkaian bahasa yang lebih luas dari kalimat. Wijana dan Rohmadi (2009:72) mengungkapkan bahwa wacana lisan bila dianalisis harus ditranskripsi dalam bentuk tulisan dahulu, dan analisis wacana pada dasarnya membahas dan menginterpretasi pesan atau makna yang dimaksud pesapa dan penyapa. 
Faktanya, bahasa tidak hanya sebagai alat untuk komunikasi dan pengetahuan tetapi juga dapat berfungsi sebagai "atribut fundamental dari identitas budaya dan pemberdayaan baik untuk individu atau kelompok". Oleh karena itu, menghormati bahasa orang-orang yang termasuk dalam komunitas linguistik yang berbeda sangat penting untuk hidup bersama secara damai (Ball, 2011).

Pengetahuan kosakata adalah salah satu indikator utama dari pengetahuan dan penggunaan bahasa (Laufer and Mclean, 2016). Semakin besar kosakata pelajar, semakin sukses mereka dalam membaca, menulis, dan kemahiran bahasa umum, serta dalam prestasi akademik (Laufer \& Ravenhorst-Kalovski, 2010; Nation, 2006). Oleh karena itu, tidak mengherankan bahwa mengukur kosakata global seseorang dalam tingkat dan ukuran telah menjadi perhatian utama dalam agenda penelitian ahli bahasa dan pendidik terapan. Penggunaan bahasa Indonesia yang tepat juga wajib dikuasai tidak hanya oleh guru bahasa Indonesia, tetapi juga para pejabat negara negara. Sebagai pejabat negara di Indonesia yang menjadi suri teladan, seyogyanya tidak hanya menguasai bahasa asing seperti bahasa Inggris, tetapi juga menguasai bahasa negara dan bahasa nasional, yakni bahasa Indonesia yang sesuai dengan Kamus Besar Bahasa Indonesia (KBBI) dan Pedoman Umum Ejaan Bahasa Indonesia (PUEBI). Oleh sebab itu, dirasa sangat penting terus mengkaji variasi diksi dalam wacana lisan yang digunakan para elite politik dalam forum-forum resmi, misalnya dalam debat calon presiden dan wakil presiden.

Penelitian ini membahas interaksi atau pertuturan para peserta debat calon presiden dan wakil presiden 2019 (debat ke-5) yang ditranskipsikan menjadi sebuah teks wacana. Penelitian ini mencoba menelusuri kembali jejak berbagai tuturan politik selama kegiatan debat kelima calon presiden dan wakil presiden 2019 berlangsung. Dengan demikian, tujuan khusus penelitian ini adalah (1) untuk mendeskripsikan kata serapan yang dituturkan oleh Joko Widodo dalam Debat Calon Presiden Dan Wakil Presiden 2019 (Debat Ke-5) pada Kanal Youtube Liputan6.Com; (2) untuk mendeskripsikan istilah asing yang dituturkan Joko Widodo dalam Debat Calon Presiden dan Wakil Presiden 2019 (Debat Ke-5) pada Kanal Youtube Liputan6.Com. 
Penelitian yang mengkaji diksi dan gaya bahasa sangatlah banyak. Salah satunya adalah tesis berjudul "Eufemisme Dalam Debat Capres Indonesia” karya Wahyuningsih (2020) yang mengulas debat capres di Indonesia merupakan suatu fenomena penggunaan bahasa yang melibatkan eufemisme yang meliputi jenis-jenis dan fungsi eufemisme, pengaruh aspek sosial budaya terhadap penggunaan eufemisme dan implikasi dari penggunaan eufemisme. Selain itu, ada pula penelitian berjudul "Prabowo Subianto dalam Debat Pilpres 2019" karya Hartinah dan Kindi(2020). Adapun hasil penelitian ini adalah penggunaan gaya bahasa Prabowo Subianto yang terdapat dalam debat pilpres 2019 adalah gaya bahasa yang berdasarkan persamaan makna berupa pleonasme dan repetisi, berdasarkan oposisi makna berupa majas paradoks, dan penggunaan gaya bahasa penegasan pertentangan berupa antithesis. Kemudian penggunaan gaya bahasa yang lebih dominan dalam pelaksanaan debat pilpres 2019 adalah pemakaian gaya bahasa sindiran berupa ironi dan sinisme dan gaya bahasa perbandingan berupa asosiasi, perumpamaan dan litotes.

Berdasakarkan kedua penelitian relevan terkait variasi bahasa pada debat capres dan cawapres di atas, ada persamaan dan perbedaan dengan penelitian ini. Persamaannya adalah mengkaji unsur diksi dalam ajang debat capres dan cawapres RI tahun 2019. Namun, unsur yang menjadi pembeda adalah fokus penelitian ini lebih menyoroti kata serapan dan istilah yang dituturkan oleh Joko Widodo dalam Debat Calon Presiden Dan Wakil Presiden 2019 (Debat Ke5) pada Kanal Youtube Liputan6.Com. Dengan demikian, penelitian ini adalah penelitian yang penting untuk dilaksanakan agar kajian tentang penggunaan kata serapan dan istilah asing dalam ragam lisan dapat menjadi sebuah penelitian mutakhir yang dapat menjadi rujukan valid para peneliti, khususnya tentang tuturan khas dari seorang negarawan.

\section{B. KAJIAN TEORI}

Kata serapan sudah sesuatu yang umum ada di antara bahasa. Proses serap-menyerap kata terjadi setiap kali ada kontak bahasa yang bersifat terbuka atau mudah menerima pengaruh sehingga dalam kontak bahasa proses serap-menyerap unsur asing akan terjadi. Hal ini bisa dikarenakan adanya kebutuhan dan kemampuan seseorang yang kurang memahami bahasa sendiri. Dalam proses penyerapan bahasa, pasti akan timbul perubahan-perubahan. Sebab, tidak ada proses penyerapan yang terjadi secara utuh. Proses penyerapan terjadi dengan beberapa penyesuaian, baik dalam ejaan antarbahasa maupun ucapan bahasa Indonesia. Pusat Pembinaan dan Pengembangan 
Bahasa (2005: 55) menyebutkan bahwa jika dalam bahasa Indonesia atau bahasa serumpun tidak ditemukan istilah yang tepat, maka bahasa asing dapat dijadikan sumber peristilahan Indonesia. Istilah baru dapat dibentuk dengan jalan menerjemahkan, menyerap, dan menyerap sekaligus menerjemahkan.

Kata serapan didefinisikan sebagai kata-kata yang memiliki bentuk fonologis serupa dan memiliki arti serupa dalam dua bahasa. Bentuk fonologis belum tentu identik dan mungkin telah mengalami beberapa penyesuaian fonologis terhadap bahasa tertentu yang meminjam kata tersebut. Kata serapan adalah kata-kata yang diambil dari bahasa asing dan diintegrasikan ke dalam bahasa Indonesia. Kata serapan sendiri sering dikenal dengan kata adaptasi atau kata retribusi. Meskipun berasal dari bahasa asing, kata serapan sudah menjadi bagian dari bahasa Indonesia dan digunakan oleh masyarakat umum dalam percakapan sehari-hari (Devianty, 2016). Dengan demikian, pengaruh bahasa daerah dan bahasa asing dalam bahasa Indonesia sudah lumrah dan sebagai bukti bahwa bahasa Indonesia semakin berkembang. Pengaruh tersebut diperlukan untuk meningkatkan kosakata kosakata bahasa Indonesia. Dengan demikian, sikap menutup pengaruh bahasa lain itu sangat merugikan perkembangan bahasa Indonesia menjadi bahasa yang modern dan sempurna. Simatupang (dalam Devianty, 2016) menjabarkan bahwa bahasa Inggris saja pada tahap perkembangannya banyak dipengaruhi oleh bahasa asing. Bahkan pernah dihitung serapan kata bahasa asing yang terdapat dalam bahasa Inggris jauh lebih besar dari kosakata bahasa Inggris aslinya, yaitu Anglo Saxon.

Selain adanya kata serapan, kerap kali muncul istilah bahasa asing dalam komunikasi seharihari, baik dalam ragam tulis maupun ragam lisan. Istilah-istilah bahasa asing yang dipadankan dengan bahasa Indonesia sampai saat initerus bertambah dan beragam (Megawati, 2019). Pembentukan kata atau istilah ke dalam bahasa Indonesia menurut Chaer (2012:169) bahwa bentuk dasar atau kosakata dalam bahasa fleksi dan aglutunasi (bahasa asing) harus dibentuk terlebih dahulu menjadi sebuah kata gramatikal melalui proses afiksasi, proses reduplikasi, dan proses komposisi.

Dalam Pedoman Umum Pembentukan Istilah (2005), proses pembentukan istilah perlu diperhatikan persyaratan dalam pemanfaatan kosakata bahasa Indonesia yaitu, (1) istilah yang dipilih adalah kata atau frasa yang paling tepat untukmengungkapkan konsep termaksud dan yang tidak menyimpang dari makna itu, (2) istilahyang dipilih adalah kata atau frasa yang paling singkat di antara pilihan yang tersedia yang mempunyai rujukan sama. (3) istilah yang dipilih adalah kata 
atau frasa yang bernilai rasa(konotasi) baik, (4) istilah yang dipilih adalah kata atau frasa yang sedap didengar (eufonik), dan (5) istilah yang dipilih adalah kata atau frasa yang bentuknya seturut kaidah bahasa Indonesia.Istilah bahasa asing akan muncul jika istilah-istilah tersebut belum terdapat dan belum ditemukan padanan katanya (Waridah, 2008:51). Istilah-istilah asing adalah istilah yang diambil dari bahasa Inggris dan digunakan untuk berbagai macam disiplin ilmu. Katakata atau istilah-istilah pun dapat dibentuk dengan melalui proses pemadanan, menerjemahkan secara langsung atau pun menerjemahkan dengan perekaan, menyerap istilah atau menyerap afiks asing sesuai ejaan, dan menyerap sekaligus menerjemahkan istilah asing (Pedoman Pembentukan Istilah, 2008:12-34).

\section{METODE PENELITIAN}

Penelitian ini menggunakan metode deskriptif kualitatif. Data-data dalam penelitian ini berupa deskripsi, yakni data tuturan. Data penelitian ini adalah tuturan Joko Widodo dalam debat calon presiden dan wakil presiden 2019 (debat ke-5) di kanal Youtube liputan6.com. Data adalah fakta yang dapat ditarik menjadi suatu kesimpulan dalam kerangka yang diteliti. Data juga bisa berupa berupa objek dari hasil penelitian yang dikumpulkan dari sumber yang bersangkutan.

Data pada penelitian ini ada dua, yaitu data primer dan data sekunder. Data primer pada data ini berupa video streaming debat calon presiden dan wakil presiden 2019 (debat ke-5) yang didapat pada kanal Youtube liputan6.com. Di sisi lain, data sekunder yang digunakan dalam penelitian ini adalah beberapa kumpulan jurnal nasional, jurnal internasional, dan buku yang terkait dengan pembahasan kata serapan dan istilah asing. Dalam proses pengumpulan data primer, metode yang digunakan adalah metode simak dengan teknik lanjutan berupa teknik catat (Sudaryanto, 2015). Teknik pengumpulan data menggunakan metode simak dengan teknik catat sebagai teknik lanjutannya. Data tuturan berjumlah 107 data tuturan.

Analisis data primer menggunakan metode agih dengan teknik bagi unsur langsung dan metode padan referensial. Metode penyajian hasil kajian ini menggunakan metode informal, yakni penyajian hasil analisis berupa pernyataan (kalimat) secara kualitatif. Hasil penelitian dipaparkan dalam bentuk pernyataan. 


\section{HASIL PENELITIAN}

Pada penelitian ini, data primer berjumlah 107 data tuturan. Data tersebut berupa tuturan dari Joko Widodo dalam debat calon presiden dan wakil presiden 2019 (debat ke-5) di kanal Youtube liputan6.com. Dari data tersebut, ditemukan 35 data tuturan yang mengandung kata serapan (32, $7 \%)$ dan 25 data tuturan yang mengandung istilah asing $(23,4 \%)$.

\section{Kata Serapan}

Kata serapan merupakan kata-kata dari bahasa asing yang masuk ke dalam bahasa Indonesia dan diperlukan untuk memperkaya bahasa Indonesia, serta dalam perkembangannya menjadi milik tetap bahasa Indonesia. Ada 36 data tuturan Joko Widodo yang menggunakan kata serapan, yakni data $03,12,14,16,18,19,21,21,22,23,29,31,33,34,37,38,40,44,45,46,47,49,50,51,52$, $54,56,58,59,60,63,65,66,68,73$, dan 88. Berikut tabel 1 ringkasan hasil analisis kata serapan pada tuturan dari Joko Widodo dalam debat calon presiden dan wakil presiden 2019 (debat ke-5) di kanal Youtube liputan6.com.

Tabel 1 Kata Serapan

\begin{tabular}{|c|c|c|c|c|}
\hline \multirow[t]{2}{*}{ No. } & \multirow{2}{*}{$\begin{array}{l}\text { No. } \\
\text { Data }\end{array}$} & \multirow{2}{*}{ Tuturan } & \multicolumn{2}{|c|}{ Keterangan } \\
\hline & & & $\begin{array}{c}\text { Asal } \\
\text { Kata Serapan }\end{array}$ & Makna Kata \\
\hline 1 & 03 & $\begin{array}{l}\text { Karena Oleh sebab itu, kami membangun } \\
\text { infrastruktur tidak di Jawa saja, tidak Jawa } \\
\text { sentris, tetapi Indonesia sentris. (20:29) }\end{array}$ & $\begin{array}{l}\text { infrastructure } \\
\text { centric }\end{array}$ & $\begin{array}{l}\text { prasarana } \\
\text { mempunyai sesuatu } \\
\text { sebagai pusat } \\
\text { perhatian, kegiatan, } \\
\text { dan sebagainya }\end{array}$ \\
\hline 2 & 12 & $\begin{array}{l}\text { Yang kita harapkan ibu-ibu dapat membeli } \\
\text { sembako dengan harga yang sudah didiskon } \\
\text { oleh pemerintah, karena ini akan kita subsidi. } \\
(20: 33)\end{array}$ & subsidy & $\begin{array}{l}\text { bantuan uang dan } \\
\text { sebagainya kepada } \\
\text { yayasan, perkumpulan, } \\
\text { dan sebagainya } \\
\text { (biasanya dari pihak } \\
\text { pemerintah) }\end{array}$ \\
\hline 3 & 14 & $\begin{array}{l}\text { Sehingga strategi ke depan baik di } \\
\text { bidang perikanan maupun di bidang } \\
\text { pertanian adalah hilirisasi, adalah } \\
\text { industrialisasi. (20:44) }\end{array}$ & industrialization & $\begin{array}{l}\text { 'usaha menggalakkan } \\
\text { industri dalam suatu } \\
\text { negara; pengindustrian' }\end{array}$ \\
\hline 4 & 16 & $\begin{array}{l}\text { kita harus berani melakukan hilirisasi } \\
\text { mencegah agar ekspor kita tidak dalam } \\
\text { bentuk mentahan tetapi minimal barang } \\
\text { setengah jadi. (20:44) }\end{array}$ & export & $\begin{array}{l}\text { 'pengiriman barang } \\
\text { dagangan ke luar } \\
\text { negeri' }\end{array}$ \\
\hline
\end{tabular}




\begin{tabular}{|c|c|c|c|c|}
\hline 5 & 18 & $\begin{array}{l}\text { Pak Prabowo, Pak Sandi, mengelola } \\
\text { ekonomi makro itu berbeda dengan } \\
\text { mengelola ekonomi mikro. Karena ekonomi } \\
\text { makro itu agregat produksi dan sisi, sisi } \\
\text { permintaan dan sisi suplai itu harus } \\
\text { dipengarui oleh dan dijaga oleh kebijakan- } \\
\text { kebijakan pemerintah. }(20: 48)\end{array}$ & $\begin{array}{l}\text { macro } \\
\text { micro } \\
\text { supply }\end{array}$ & $\begin{array}{l}\text { berkaitan dengan } \\
\text { jumlah yang banyak } \\
\text { atau ukuran yang } \\
\text { besar' } \\
\text { berkaitan dengan } \\
\text { jumlah yang sedikit } \\
\text { atau ukuran yang kecil } \\
\text { persediaan barang- } \\
\text { barang yang } \\
\text { dibutuhkan dan dapat } \\
\text { diperoleh }\end{array}$ \\
\hline 6 & 19 & $\begin{array}{l}\text { Kalau kita berhadapan dengan ekonomi } \\
\text { mikro ini hanya jual dan beli, hanya } \\
\text { membangun industri kemudian menjualya, } \\
\text { produk yang ada. (20:48) }\end{array}$ & product & $\begin{array}{l}\text { barang atau jasa yang } \\
\text { dibuat dan ditambah } \\
\text { gunanya atau nilainya } \\
\text { dalam proses produksi } \\
\text { dan menjadi hasil akhir } \\
\text { dari proses produksi itu }\end{array}$ \\
\hline 7 & 20 & $\begin{array}{l}\text { Tetapi ekonomi makro adalah mengelola } \\
\text { agregat-agregat produksi, kemudian sektor } \\
\text { sekunder di bidang manufaktur, saya kira } \\
\text { tidak semudah itu, artinya memerlukan } \\
\text { tahapan-tahapan besar. (20:49) }\end{array}$ & $\begin{array}{l}\text { sector } \\
\text { manufacture }\end{array}$ & $\begin{array}{l}\text { lingkungan suatu usaha } \\
\text { proses mengubah } \\
\text { bahan mentah menjadi } \\
\text { barang untuk dapat } \\
\text { digunakan atau } \\
\text { dikonsumsi oleh } \\
\text { manusia }\end{array}$ \\
\hline 8 & 23 & $\begin{array}{l}\text { Sudah berkali-kali saya sampaikan bahwa } \\
\text { tahapan besar pertama adalah pembangunan } \\
\text { insfrastruktur, kita fokus. Tahapan kedua } \\
\text { adalah pembangunan sumber daya manusia. } \\
\text { Yang ketiga adalah reformasi struktural. } \\
\text { Dan yang keempat, urusan teknologi dan } \\
\text { inovasi. (20:49) }\end{array}$ & $\begin{array}{l}\text { focus } \\
\text { reformation } \\
\text { structural } \\
\text { innovation }\end{array}$ & $\begin{array}{l}\text { memusatkan perhatian } \\
\text { perubahan secara } \\
\text { drastis untuk perbaikan } \\
\text { (bidang sosial, politik, } \\
\text { atau agama) dalam } \\
\text { suatu masyarakat atau } \\
\text { negara } \\
\text { berkenaan dengan } \\
\text { struktur } \\
\text { pemasukan atau } \\
\text { pengenalan hal-hal } \\
\text { yang baru; } \\
\text { pembaruan }\end{array}$ \\
\hline 9 & 29 & $\begin{array}{l}\text { Apabila jalan ini sudah kita koreksi benar, } \\
\text { akan kita besarkan sebesar-besarnya, } \\
\text { sehingga wanita indonesia, perempuan- } \\
\text { perempuan indonesia Indonesia produktif } \\
\text { dan juga bisa memberikan income tambahan } \\
\text { bagi rumah tangga. (21:01) }\end{array}$ & $\begin{array}{l}\text { correction } \\
\text { productive }\end{array}$ & $\begin{array}{l}\text { pembetulan; } \\
\text { pemeriksaan } \\
\text { bersifat atau mampu } \\
\text { menghasilkan (dalam } \\
\text { jumlah besar) }\end{array}$ \\
\hline
\end{tabular}




\begin{tabular}{|c|c|c|c|c|}
\hline 10 & 33 & $\begin{array}{l}\text { Oleh sebab itu yang ingin kita kerjakan } \\
\text { adalah menaikkan tax ratio secara gradual, } \\
\text { dengan membangun sebuah tax base } \\
\text { sebanyak-banyaknya dan itu sudah kita } \\
\text { lakukan sejak kita melakukan tax amnesty. } \\
(21: 14)\end{array}$ & gradual & $\begin{array}{l}\text { berangsur-angsur; } \\
\text { sedikit demi sedikit }\end{array}$ \\
\hline 11 & 34 & $\begin{array}{l}\text { Tax amnesty ada deklarasi } 4.800 \text { triliun dan } \\
\text { kita mendapatkan income dari sana } 114 \\
\text { triliun tahun itu. (21:14) }\end{array}$ & declaration & $\begin{array}{l}\text { pernyataan ringkas dan } \\
\text { jelas (tentang suatu hal) }\end{array}$ \\
\hline 12 & 38 & $\begin{array}{l}\text { Ya soal zakat dan wakaf ini sebenarnya kita } \\
\text { sudah punya lembaganya, lembaga } \\
\text { BAZNAS, BAZLAS dan juga badan wakaf. } \\
(21: 15)\end{array}$ & $\begin{array}{l}\text { زakat } \\
\text { Zak وَقَّتَ } \\
\text { waqf }\end{array}$ & $\begin{array}{l}\text { salah satu rukun Islam } \\
\text { yang mengatur harta } \\
\text { yang wajib dikeluarkan } \\
\text { kepada mustahik } \\
\text { benda bergerak atau } \\
\text { tidak bergerak yang } \\
\text { disediakan untuk } \\
\text { kepentingan umum } \\
\text { (Islam) sebagai } \\
\text { pemberian yang ikhlas }\end{array}$ \\
\hline 13 & 45 & $\begin{array}{l}\text { Menurut saya di bidang penerimaan pajak, } \\
\text { kalau kita } \text { konsisten melakukan reformasi di } \\
\text { bidang pajak, pelayanan pajak, online } \\
\text { pajak.... (21:18) }\end{array}$ & consistent & $\begin{array}{l}\text { tetap (tidak berubah- } \\
\text { ubah); taat asas; ajek }\end{array}$ \\
\hline 14 & 44 & $\begin{array}{l}\text { Sebagai negara dengan penduduk muslim } \\
\text { terbesar di dunia, kita memiliki sebuah } \\
\text { kekuatan besar di dalam keuangan syariah, } \\
\text { ekonomi syariah dan kita tahu bahwa } \\
\text { Indonesia sekarang ini dinobatkan sebagai } \\
\text { nomor satu di bidang wisata halal. }(21: 23)\end{array}$ & $\begin{array}{l}\text { الثريعة } \\
\text { alshrye } \\
\text { حلال } \\
\text { halal }\end{array}$ & $\begin{array}{l}\text { Syariat 'hukum agama } \\
\text { yang menetapkan } \\
\text { peraturan hidup } \\
\text { manusia, hubungan } \\
\text { manusia dengan Allah } \\
\text { Swt., hubungan } \\
\text { manusia dengan } \\
\text { manusia dan alam } \\
\text { sekitar berdasarkan } \\
\text { Alquran dan hadis' } \\
\text { diizinkan (tidak } \\
\text { dilarang oleh syarak) }\end{array}$ \\
\hline 15 & 47 & $\begin{array}{l}\text { Ya tadi saya ingin melanjutkan mengenai } \\
\text { wisata halal kita yang sudah ditetapkan } \\
\text { menjadi nomor satu di dunia. Ini di dunia, ini } \\
\text { kita akan fokus dan konsentrasi di sini } \\
\text { dengan produk-produk halal yang sudah tadi } \\
\text { saya sampaikan juga. }(21: 27)\end{array}$ & concentration & $\begin{array}{l}\text { pemusatan perhatian } \\
\text { atau pikiran pada suatu } \\
\text { hal }\end{array}$ \\
\hline 16 & 49 & $\begin{array}{l}\text { Pertanyaan kami singkat. Apa yang akan } \\
\text { Bapak Prabowo lakukan dalam rangka } \\
\text { pengembangan ekonomi digital? (21:39) }\end{array}$ & digital & $\begin{array}{l}\text { berhubungan dengan } \\
\text { angka-angka untuk } \\
\text { sistem perhitungan } \\
\text { tertentu; berhubungan } \\
\text { dengan penomoran }\end{array}$ \\
\hline
\end{tabular}




\begin{tabular}{|c|c|c|c|c|}
\hline 17 & 50 & $\begin{array}{l}\text { Kita sebagai pemerintah memang harus cepat } \\
\text { tanggap dan respon cepat terhadap } \\
\text { perubahan-perubahan global yang saat ini } \\
\text { terjadi. }(21: 42)\end{array}$ & $\begin{array}{l}\text { response } \\
\text { global }\end{array}$ & $\begin{array}{l}\text { Respons 'tanggapan; } \\
\text { reaksi; jawaban' } \\
\text { bersangkut paut, } \\
\text { mengenai, meliputi } \\
\text { seluruh dunia }\end{array}$ \\
\hline 18 & 52 & $\begin{array}{l}\text { Yang kedua membangun } \text { ekosistem yang } \\
\text { nyaman bagi mereka terus berusaha } \\
\text { membuat game dan ini saya kira sebuah } \\
\text { peluang yang besar bagi industri game di } \\
\text { Indonesia. (21:43) }\end{array}$ & $\begin{array}{l}\text { ecosystem } \\
\text { industry }\end{array}$ & $\begin{array}{l}\text { keanekaragaman suatu } \\
\text { komunitas dan } \\
\text { lingkungannya yang } \\
\text { berfungsi sebagai suatu } \\
\text { satuan ekologi dalam } \\
\text { alam } \\
\text { kegiatan memproses } \\
\text { atau mengolah barang } \\
\text { dengan menggunakan } \\
\text { sarana dan peralatan }\end{array}$ \\
\hline 19 & 54 & $\begin{array}{l}\text { Oleh sebab itu jangan sampai kita terlewat } \\
\text { merespon setiap perubahan-perubahan yang } \\
\text { ada. Ini juga harus dilihat dan diwaspadai } \\
\text { sehingga kita merespon dengan regulasi- } \\
\text { regulasi yang benar. Kemudian juga menjadi } \\
\text { pemain } \text { e-sport yang profesional itu butuh } \\
\text { sebuah fisik yang baik, butuh latihan-latihan } \\
\text { yang detail sehingga betul-betul nanti jadi } \\
\text { profesional dunia. (21:44) }\end{array}$ & $\begin{array}{l}\text { regulation } \\
\text { professional }\end{array}$ & $\begin{array}{l}\text { Pengaturan } \\
\text { memerlukan } \\
\text { kepandaian khusus } \\
\text { untuk menjalankannya }\end{array}$ \\
\hline 20 & 56 & $\begin{array}{l}\text { Apa yang ingin kita lakukan ke depan, } \\
\text { substitusi barang-barang impor itu harus } \\
\text { dikerjakan di Indonesia. Petrochemical, } \\
\text { energi, industrinya harus ada di Indonesia, } \\
\text { karena impor terbesar impor kita ada di situ. } \\
(21: 49)\end{array}$ & substitution & penggantian \\
\hline 21 & 60 & $\begin{array}{l}\text { Itu harus pakai L/C untuk membatasi agar } \\
\text { tidak terjadi transfer pricing antara kita } \\
\text { dengan pembeli-pembeli yang ada di luar. } \\
(21: 51)\end{array}$ & transfer & $\begin{array}{l}\text { pindah atau beralih } \\
\text { tempat }\end{array}$ \\
\hline 22 & 65 & $\begin{array}{l}\text { Bukan ekonomi mikro yang kita } \\
\text { bicarakan dan ini ekonomi negara. Jadi } \\
\text { sangat berbeda sekali kita harus mengerti } \\
\text { dari sisi suplai dari sisi demandnya, secara } \\
\text { garis besar seperti apa harus betul-betul } \\
\text { harus memakai angka-angka yang didasarkan } \\
\text { dari data-data dan dari survei-survei. (21:55) }\end{array}$ & survey & $\begin{array}{l}\text { teknik riset dengan } \\
\text { memberi batas yang } \\
\text { jelas atas data; } \\
\text { penyelidikan; } \\
\text { peninjauan }\end{array}$ \\
\hline 23 & 68 & $\begin{array}{l}\text { Oleh sebab itu } \boldsymbol{B} \boldsymbol{U} \boldsymbol{M N} \text { kita ke depan harus } \\
\text { berani keluar dari kandang untuk menjadi } \\
\text { pionir keluar negeri, membuka pasar, } \\
\text { membuka jaringan-jaringan, membuka } \\
\text { holding-holding yang besar seperti itu. } \\
\text { (22:08) }\end{array}$ & pioneer & $\begin{array}{l}\text { cak penganjur; pelopor; } \\
\text { perintis jalan; pembuka } \\
\text { jalan }\end{array}$ \\
\hline
\end{tabular}




\begin{tabular}{l|l|l|l|l}
\hline 24 & 73 & $\begin{array}{l}\text { Kalau kita selalu memandang segala sesuatu } \\
\text { dengan pesimis, tidak ada negara maju di } \\
\text { manapun kalau rakyatnya pesimis, gak akan } \\
\text { mungkin. Tidak ada negara maju di manapun } \\
\text { kalau rakyatnya enggak optimis bahwa ada } \\
\text { tantangan, bahwa ada masalah, bahwa ada } \\
\text { problem. (22:13) }\end{array}$ & problem \\
25 & 88 & $\begin{array}{l}\text { Tetapi kita wajib bersyukur, kita jangan kufur } \\
\text { nikmat, inflasi yang terus terjaga, inflasi } \\
\text { pangan yang rendah, tingkat pengangguran } \\
\text { yang terus turun, kemiskinan yang juga } \\
\text { sudah satu digit, ini wajib kita syukuri. } \\
\text { (22:33) }\end{array}$ & $\begin{array}{l}\text { (shukraan) } \\
\text { optimis; penuh harapan } \\
\text { (tentang sikap) }\end{array}$ \\
\end{tabular}

Berdasarkan tabel 1 di atas, fakta kebahasaan tentang penggunaan kata serapan dalam tuturan yang disampaikan oleh Joko Widodo saat debat calon presiden dan wakil presiden 2019 (debat ke5) berjumlah 36 data. Kata serapan yang berasal dari bahasa Inggris, yakni kata infrastructure, centric, subsidy, industrialization, export, macro, micro, supply, product, sector, manufacture, focus, reformation, structural, innovation, correction, gradual, declaration, consistent, concentration, digital, response, global, ecosystem, regulation, professional, industry, substitution, transfer, survey, pioneer, optimistic, dan problem. Berdasarkan data tersebut, ternyata kata serapan yang paliing dominan adalah kata di dalam bidang ekonomi, seperti kata subsidy, industrialization, export, macro, micro, supply, product, sector, manufacture, transfer.

Selain data di atas, ada pula 5 kata serapan dari bahasa Arab pada 6 data tuturan Joko Widodo yang identik dengan bidang keagamaan (khususnya di bidang agama Islam dan ekonomi yang berlandaskan agama Islam), yakni زكاة (zakat), وَقَّف (wakaf), الشريعة (syariah), حلال (halal), dan I شكر (shukraan). Hasil temuan ini sesuai dengan hasil penelitian terdahulu, tepatnya tesis berjudul "Eufemisme Dalam Debat Capres Indonesia" karya Wahyuningsih (2020), yakni kata serapan dan pinjaman, jenis ini dituturkan oleh kedua kandidat dengan intensitas tidak jauh berbeda mesikupun Joko Widodo terlihat lebih unggul.

\section{Istilah Asing}

Istilah asing merupakan kata atau istilah yang diambil dari bahasa asing dan digunakan untuk berbagai macam disiplin ilmu. Kata-kata atau istilah-istilah pun dapat dibentuk dengan melalui proses pemadanan, menerjemahkan secara langsung atau pun menerjemahkan dengan perekaan, menyerap istilah atau menyerap afiks asing sesuai ejaan, dan menyerap sekaligus 
menerjemahkan istilah asing (Pedoman Pembentukan Istilah, 2008:12 - 34). Ada 25 data tuturan Joko Widodo yang menggunakan istilah asing, yakni 10, 15, 17, 29, 32, 34, 35, 36, 40, 41, 45, 51, $52,54,56,57,59,61,65,67,68$, dan 88. Berikut tabel 2 ringkasan hasil analisis istilah asing yang terdapat dalam tuturan dari Joko Widodo dalam debat calon presiden dan wakil presiden 2019 (debat ke-5) di kanal Youtube liputan6.com.

\section{Tabel 2 Istilah Asing}

\begin{tabular}{|c|c|c|c|}
\hline No. & $\begin{array}{l}\text { No. } \\
\text { Data }\end{array}$ & Tuturan & Makna Kata \\
\hline 1 & 10 & $\begin{array}{l}\text { Dan dengan Kartu Pra Kerja ini, kita akan melakukan pelatihan- } \\
\text { pelatihan, training-training, baik di dalam negeri maupun di luar } \\
\text { negeri. (20:32) }\end{array}$ & training 'latihan' \\
\hline 2 & 15 & $\begin{array}{l}\text { Perlu dibangun industri-industri perikanan sebanyak-banyaknya, } \\
\text { pengolahan, pengalengan sehingga kita mengekspor dalam bentuk } \\
\text { barang-barang yang sudah olahan, sudah packaging di sini, sudah di } \\
\text { labeling, sudah dibangun brand dari sini. (20:44) }\end{array}$ & $\begin{array}{l}\text { packaging 'pengemasan' } \\
\text { labeling 'pelabelan' } \\
\text { brand 'merek' }\end{array}$ \\
\hline 3 & 17 & $\begin{array}{l}\text { Kita tahu anak-anak muda sekarang sudah membangun ekosistem } \\
\text { online yang kalau ini bisa disambungkan dengan ekosistem offline } \\
\text { dari produk-produk pertanian akan memudahkan petani-petani } \\
\text { langsung berhubungan dengan konsumen, berhubungan dengan } \\
\text { pembeli lewat digital ekonomi. (20:45) }\end{array}$ & $\begin{array}{l}\text { Online 'dalam jaringan/daring' } \\
\text { Offline 'luar jaringan/luring' }\end{array}$ \\
\hline 4 & 29 & $\begin{array}{l}\text { Apabila jalan ini sudah kita koreksi benar, akan kita besarkan } \\
\text { sebesar-besarnya, sehingga wanita indonesia, perempuan-perempuan } \\
\text { indonesia Indonesia produktif dan juga bisa memberikan income } \\
\text { tambahan bagi rumah tangga. (21:01) }\end{array}$ & Income 'pendapatan' \\
\hline 5 & 32 & $\begin{array}{l}\text { Kalau dalam setahun naiknya drastis seperti itu, artinya akan ada 5\% } \\
\text { kurang lebih. 5\% dari GDP } 15 \text { triliun rupiah. 5\% artinya } 750 \text { triliun } \\
\text { yang itu akan ditarik menjadi pajak. Apa yang terjadi kalau itu } \\
\text { dilakukan? Akan terjadi shock economy. (21:14) }\end{array}$ & $\begin{array}{l}\text { shock economy 'ekonomi } \\
\text { kejutan' }\end{array}$ \\
\hline 6 & 33 & $\begin{array}{l}\text { Oleh sebab itu yang ingin kita kerjakan adalah menaikkan tax ratio } \\
\text { secara gradual, dengan membangun sebuah tax based sebanyak- } \\
\text { banyaknya dan itu sudah kita lakukan sejak kita melakukan tax } \\
\text { amnesty. }(21: 14)\end{array}$ & $\begin{array}{l}\text { tax ratio 'rasio pajak' } \\
\text { tax based 'berbasis pajak' } \\
\text { tax amnesty 'pengampunan } \\
\text { pajak' }\end{array}$ \\
\hline 11 & 41 & $\begin{array}{l}\text { Sekarang Bapak menyampaikan SPT tahunan itu lewat } \boldsymbol{e} \text {-Filing } \\
\text { sudah bisa dari rumah bisa, jam berapapun bisa diterima.inilah } \\
\text { reformasi di bidang perpajakan yang telah kita lakukan. (21:18) }\end{array}$ & e-Filing 'Pengarsipan elektronik' \\
\hline 12 & 45 & $\begin{array}{l}\text { ini alhamdulillah dan juga sebentar lagi kita akan membuka halal } \\
\text { lapak di dekat GBK. (21:23) }\end{array}$ & $\begin{array}{l}\text { الحمد لله'Pujian itu hanya untuk } \\
\text { Allah' }\end{array}$ \\
\hline
\end{tabular}




\begin{tabular}{|c|c|c|c|}
\hline 13 & 51 & $\begin{array}{l}\text { Oleh sebab itu pemerintah membangun infrastruktur digital baik } \\
\text { broadband dengan kecepatan tinggi palapa ring, } \mathbf{4} \boldsymbol{G} \text { sehingga anak- } \\
\text { anak muda kita memiliki infrastruktur dalam mengembangkan } \\
\text { profesinya sebagai gamers. }(21: 42)\end{array}$ & $\begin{array}{l}\text { broadband 'teknik transmisi } \\
\text { berkapasitas tinggi yang } \\
\text { menggunakan berbagai } \\
\text { frekuensi, yang memungkinkan } \\
\text { sejumlah besar pesan } \\
\text { dikomunikasikan secara } \\
\text { bersamaan' } \\
\mathbf{4 G} \text { (fourth-generation } \\
\text { technology) 'teknologi generasi } \\
\text { keempat' } \\
\text { gamers 'pemain permainan' }\end{array}$ \\
\hline 14 & 52 & $\begin{array}{l}\text { Yang kedua membangun ekosistem yang nyaman bagi mereka terus } \\
\text { berusaha membuat game dan ini saya kira sebuah peluang yang } \\
\text { besar bagi industri game di Indonesia. }(21: 43)\end{array}$ & Game "permainan" \\
\hline 15 & 54 & $\begin{array}{l}\text { Kemudian juga menjadi pemain } \boldsymbol{e} \text {-sport yang profesional itu butuh } \\
\text { sebuah fisik yang baik, butuh latihan-latihan yang detail sehingga } \\
\text { betul-betul nanti jadi profesional dunia. (21:44) }\end{array}$ & $\begin{array}{l}\boldsymbol{e} \text {-sport 'video game multipemain } \\
\text { yang dimainkan secara } \\
\text { kompetitif untuk penonton, } \\
\text { biasanya oleh pemain } \\
\text { profesional' }\end{array}$ \\
\hline 16 & 56 & $\begin{array}{l}\text { Apa yang ingin kita lakukan ke depan, substitusi barang-barang } \\
\text { impor itu harus dikerjakan di Indonesia. Petrochemical, energi, } \\
\text { industrinya harus ada di Indonesia, karena impor terbesar impor kita } \\
\text { ada di situ. (21:49) }\end{array}$ & Petrochemical 'Petrokimia' \\
\hline 17 & 57 & $\begin{array}{l}\text { Kemudian minyak dan migas kita telah mulai membangun refinery } \\
\text { dan dengan pembangunan ini kedepan saya yakin bahwa defisit ini } \\
\text { akan kita bisa kita hilangkan. }(21: 50)\end{array}$ & Refinery 'kilang minyak' \\
\hline 18 & 59 & $\begin{array}{l}\text { Itu harus pakai L/C untuk membatasi agar tidak terjadi transfer } \\
\text { pricing antara kita dengan pembeli-pembeli yang ada di luar. (21:51) }\end{array}$ & $\begin{array}{l}\text { transfer pricing 'ongkos } \\
\text { transfer' }\end{array}$ \\
\hline 19 & 61 & $\begin{array}{l}\text { Saya kira, seperti tadi disampaikan oleh Bapak bahwa ingin mau } \\
\text { gunakan biofuel itu. Sudah itu sudah kita lakukan dan sudah kita } \\
\text { mulai dengan yang namanya B20. (21:54) }\end{array}$ & biofuel 'Bahan bakar hayati' \\
\hline 20 & 65 & $\begin{array}{l}\text { Jadi sangat berbeda sekali kita harus mengerti dari sisi suplai dari } \\
\text { sisi demandnya, secara garis besar seperti apa harus betul-betul } \\
\text { harus memakai angka-angka yang didasarkan dari data-data dan dari } \\
\text { survei-survei. (21:55) }\end{array}$ & Demand 'permintaan' \\
\hline 21 & 67 & $\begin{array}{l}\text { Iya, saya kira ke depan kita akan membangun holding-holding } \\
B U M N \text { baik holding yang berkaitan dengan konstruksi yang karya- } \\
\text { karya, Kemudian holding yang berkaitan dengan migas akan kita } \\
\text { holding-kan. (22:07) }\end{array}$ & holding 'aset' \\
\hline 23 & 88 & $\begin{array}{l}\text { Tetapi kita wajib bersyukur, kita jangan } \text { kufur nikmat, inflasi yang } \\
\text { terus terjaga, inflasi pangan yang rendah, tingkat pengangguran yang } \\
\text { terus turun, kemiskinan yang juga sudah satu digit, ini wajib kita } \\
\text { syukuri. (22:33) }\end{array}$ & $\begin{array}{l}\text { kufur لكفر } \\
\text { 'ingkar; tidak pandai bersyukur' }\end{array}$ \\
\hline
\end{tabular}


Berdasarkan tabel 2 di atas, fakta kebahasaan tentang penggunaan istilah asing dalam tuturan yang disampaikan oleh Joko Widodo dalam debat calon presiden dan wakil presiden 2019 (debat ke-5) berjumlah 25 data. Istilah asing yang berasal dari bahasa Inggris berjumlah 23 data, yakni training, packaging,labeling, brand, online, offline, income, shock economy, tax ratio, tax based, tax amnesty, e-filing, broadband, 4 g (fourth-generation technology), gamers, game, e-sport, petrochemical, refinery, transfer pricing, biofuel, demand, dan holding. Selain itu, ada pula 2 istilah asing dari bahasa Arab pada 2 data tuturan Joko Widodo, yakni الحمد لله (alhamdulillah / Pujian itu hanya untuk Allah) dan kufur لكفر (ingkar; tidak pandai bersyukur).

Berdasarkan pembahasan pada 2 tabel di atas, variasi penggunaan kata serapan dan istilah asing yang dituturkan oleh Joko Widodo saat debat calon presiden dan wakil presiden 2019 (debat ke-5) umumnya berkaitan dengan kosakata bahasa Inggris. Dari 107 data tuturan yang menjadi data primer penelitian ini, ada 35 data tuturan yang mengandung kata serapan (32, 7\%) yang paling dominan jika dibandingkan dengan penggunaan istilah asing, yakni 25 data tuturan yang mengandung istilah asing $(23,4 \%)$.

\section{E. KESIMPULAN}

Berdasarkan kajia variasi kata serapan dan istilah asing yang digunakan Joko Widodo dalam debat calon presiden dan wakil presiden 2019 (debat ke-5), dapat disimpulkan bahwa yang dominan dari 107 data primer adalah 32, 7\% (36 data) penggunaan kata serapan. Penggunaan kata serapan yang dituturkan oleh Joko Widodo ketika debat calon presiden dan wakil presiden 2019 (debat ke-5) yang paling dominan adalah kosakata yang berasal dari bahasa Inggris. Di sisi lain, ada sekitar 23,4\% (25 data) tuturan yang mengandung istilah asing dan didominasi juga dari bahasa Inggris. Selain bahasa Inggris, ada pula bahasa Arab yang digunakan pada data tuturan kata serapan dan istilah asing.

\section{F. SARAN}

Penulis menyarankan agar penelitian-penelitian selanjutnya terkait analisis diksi dapat dikembangkan lagi, seperti faktor penyebab penggunaan kata serapan dan kata asing dalam sehingga bermanfaat bagi pembaca. Penulis berharap penelitian ini dapat dijadikan pengetahuan tambahan untuk menyempuranakan penggunaan bahasa terutama pada lingkup formal, juga untuk 
referensi penulis lain yang tertarik menganalisis bidang linguistik (bahasa), khususnya tentang kata serapan dan istilah asing yang kerap digunakan dalam ragam lisan dan ragam tulis.

\section{DAFTAR PUSTAKA}

Ball, J, 2011, Enhancing learning of children from diverse language backgrounds: Mother tongue-based bilingual or multi lingual education in the early years, France, 2011. (Online). http://unesdoc.unesco.org/images/0021/002122/212270e.pdf.

Chaer, A, 2012, Linguistik Umum, Jakarta, Rineka Cipta.

Devianty, Rina, 2016, Loan Words In Indonesian, Journal Vision, 9( 9) Januari - Juni 2016.

Hartinah, Y., Kindi, FM, 2020, Analisis Wacana Politik Capres Joko Widodo dan Prabowo Subianto dalam Debat Pilpres 2019, Prasasti: Journal of Linguistics, 5(1).

Kamus Besar Bahasa Indonesia (Daring), Tersedia di kbbi.kemdikbud.go.id/, Diakses 15 Februari 2020.

Keraf, Gorys, 2006, Diksi dan Gaya Bahasa, Jakarta, PT Gramedia Pustaka Utama.

Laufer, Batia; McLean, Stuart, 2016, Loanwords and Vocabulary Size Test Scores: A Case of Different Estimates for Different L1 Learners, Language Assessment Quarterly, 13(3), 202-217, doi:10.1080/15434303.2016.1210611.

Laufer, B., \& Ravenhorst-Kalovski, G. C, 2010, Lexical threshold revisited: Lexical text coverage, learners' vocabulary size and reading comprehension, Reading in a Foreign Language, 22(1), 15-30.

Megawati, B, 2019, Perkembangan Padanan Istilah Bahasa Asing dalam Bahasa Indonesia Akibat Perkembangan Ipteks. https://doi.org/10.31227/osf.io/58rk9.

Nation, I. S. P., 2006, How large a vocabulary is needed for reading and listening?, The Canadian Modern Language Review, 63(1), 59-82, doi:10.3138/cmlr.63.1.59.

Pusat Bahasa Departemen Pendidikan Nasional, 2008, Pedoman Umum Pembentukan Istilah, Jakarta, Pusat Bahasa.

Pusat Bahasa Departemen Pendidikan Nasional, 2005, Pedoman Umum Pembentukan Istilah, Jakarta, Pusat Bahasa.

Septiani , D.,; Manasikana, A., 2020, Campur Kode Pada Akun Instagram @ Demakhariini (Kajian Soiolinguistik). Jurnal Basastra, 9(3), https://doi.org/10.24114/bss.v9i3.21443.

Sudaryanto, 2015, Metode dan Aneka Teknik Analisis Bahasa, Yogyakarta, Duta Wacana UP.

Wijana, I Dewa Putu \& Muhammad Rohmadi, 2009, Analisis Wacana Pragmatik: Kajian Teori dan Analisis, Surakarta, Yuma Pustaka.

Wahyuningsih, 2020, Eufemisme Dalam Debat Capres Indonesia, Tesis, Universitas Diponegoro, Semarang.

Waridah, E, 2008, EYD \& Seputar Kebahasa-Indonesiaan, Jakarta, Kawan Pustaka. 